研 . 究

\title{
メカニカルアロイング法による $\mathrm{NbC}$ 分散 $\mathrm{Al}_{3} \mathrm{Nb}$ 複合材の作製
}

兼吉 高宏, 高橋 輝男

林 行信, 元山 宗之

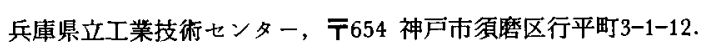

\section{Preparation of $\mathrm{NbC}$-dispersion $\mathrm{Al}_{3} \mathrm{Nb}$ Composite by Mechanical Alloying}

Takahiro Kaneyoshi, Teruo Takahashi

Yukinobu Hayashi and Muneyuki Motoyama

Hyogo Prefectural Institute of Industrial Research, 3-1-12 Yukihira-cho Suma-ku, Kobe 654.

Received March 18, 1992

Elemental $\mathrm{Al}$ and $\mathrm{Nb}$ or $\mathrm{Al}, \mathrm{Nb}$ and graphite powders were mechanically alloyed (MA) with methanol in an Ar gas atmosphere. The results of $X$-ray diffraction indicated that $\mathrm{Al}_{3} \mathrm{Nb}$ and $\mathrm{NbC}$ phases were obtained in the mixed powders mechanically alloyed longer than 72. 0ks. TEM observation of $\mathrm{HA}$ powders revealed that nano-sized crystalline $\mathrm{A} 1_{3} \mathrm{Nb}$ and $\mathrm{NbC}$ precipitated to make a small powder particle. The sintered compacts with high density were obtained by vacuum heating of the compacts of MA powders. Fine NbC particles dispersed uniformly in the sintered compacts and its content increased in proportion to graphite content. The hardness of the sintered compacts increased linearly with $\mathrm{NbC}$ content.

\section{1 緒言}

$\mathrm{Al}_{3} \mathrm{Nb}, \mathrm{Nb}{ }_{3} \mathrm{Al}$ をはじめとするAl-Nb系高融点金属間化 合物は次世代の耐熱棈造材として期待されているが, 常温延性がそしく成形が非常に困難な材料である，中 でも軽量性, 耐化性の観点からはA1側の $\mathrm{A} 1{ }_{3} \mathrm{Nb}$ が今後 有望視されると考えられる。また，より過酷な条件の 要求に対し，これら金属間化合物をマトリックスとし， セラミックス綸維あるいは粒子により強化をはかった 金属間化合物複合材料の開発が進められている。この ような材料を溶解法で作製する場合，融点の大きいあ
るいは活性な元素を用いるため，組成の制御が難しく， 結晶粒も大きくなる傾向がある。それらの改善策とし ては，微細な結晶粒が得られやすく成形が行いやすい 粉末冶金法が有効であると考えられる，一方，純元素 粉末をメカニカルアロイング (MA) ${ }^{1-8) す る こ と に よ ~}$ り，アモルファス相, 過飽和固溶体, 安定化合物など

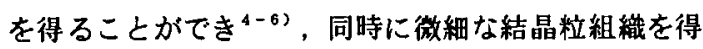
られることが明らかになっている，また，炭素，酸素 源を積極的に用いることにより，炭化物あるいは酸化 物粒子を均一微細に分散させることが可能であること 


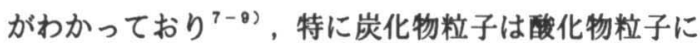
比へ，熱処理を行っても粗大化しにくく微細な粒子が 得られやすい，そこで本研究では，軽量かつ高温強度 の優れた材料を開発するため, マトリックスとして $\mathrm{Al}_{3}$ Nbを分散粒子にNbCをそれぞれ選択し, 出発材料として $\mathrm{Al}, \mathrm{Nb}$ ，黒鉛の各素粉末を用いHA処理を行うことによ り， $\mathrm{NbC}$ を微細に分散させた $\mathrm{Al}_{3} \mathrm{Nb}_{\mathrm{N}}$ 複合材を作製するこ とを試みたので報告する.

\section{2 実験方法}

出発材料として, 純Al ( 99.99 mass\%, 以後\%と略す),

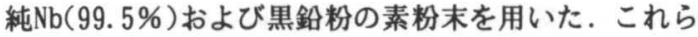
の粉末を $\mathrm{Al}_{3} \mathrm{Nb} お よ ひ ゙ A 1_{s} \mathrm{Nb}-\mathrm{xvol} \% \mathrm{NbC}(\mathrm{x}=5,10,20,30)$ の組成に配合し，助剂としてメチルアルコール約 $0.4 \mathrm{~g}$ を添加してMA処理を行った. MA処理には粉砕/混合ミ ル (Spex Co., Spex8000) を用い, Ar雾囲気中で最長 360ksまで行った.また，MA処理に用いた容器，ボール の材質はSUS304であり，ボールと粉末の質量比はおよ そ3対1である. 各時間MA処理を行った粉末をサンプリ ングし，X線回折測定（CuK $\alpha$ ），SEMおよびTEM観察を 行った。また,粉末を樹脂に埋め込み,断面組織の観察, マイクロビッカース硬度計による硬さ測定を行った． MA粉末の一部は1GPaで圧粉成形後, 1073Kおよび1473K の温度で3.6ks真空熱処理を行った. 焼結体はX $\mathrm{X}$ 線回折 測定（CuK $\alpha) ，$ SEM钽察マイクロビッカース硬度計に よる硬さ測定を行った.

\section{3 実験結果およひ考察}

$\mathrm{Al}_{3} \mathrm{Nb}$ 組成に配合し, MA処理を行った粉末（以後， Al-Nb系MA粉末之呼ぶ）の外観および断面組織をPhoto. にに示す. 14.4 28.8ksのMA処理では, 原料粉末の粉砕, 凝着が繰り返された粒子径が数十 $\mu \mathrm{m}$ の比較的大きな 粉末粒子であるが, $72.0 \mathrm{ksMA}$ 処理を行った粉末は, 14.4， 28.8ksのMA処理粉末と比へでったく異なった外観を 示しており,大きさが数 $\mu$ mの非常に微細な粒子となっ ていることがわかる. 断面組織についても28.8ksMA処 理を行った粉末はAl, Nbのラメラ組織となっているが, 72. 0ksのMA処理粉末では非常に均質な組織が得られて いる.

Al-Nb系MA粉末のMA処理時間にともなうX $\mathrm{X}$ 線回折図 形の変化をFig. 1に示す. Al, Nbの回折ピークはMA処理 時間の增加にともない减少し, 28.8ksMA処理を行った 粉末ではA1, Nb以外にNbの回折ピークの約 $1 \sim 2^{\circ}$ 低角 側に矢印で示した新たな回折ピークが現われてくる.
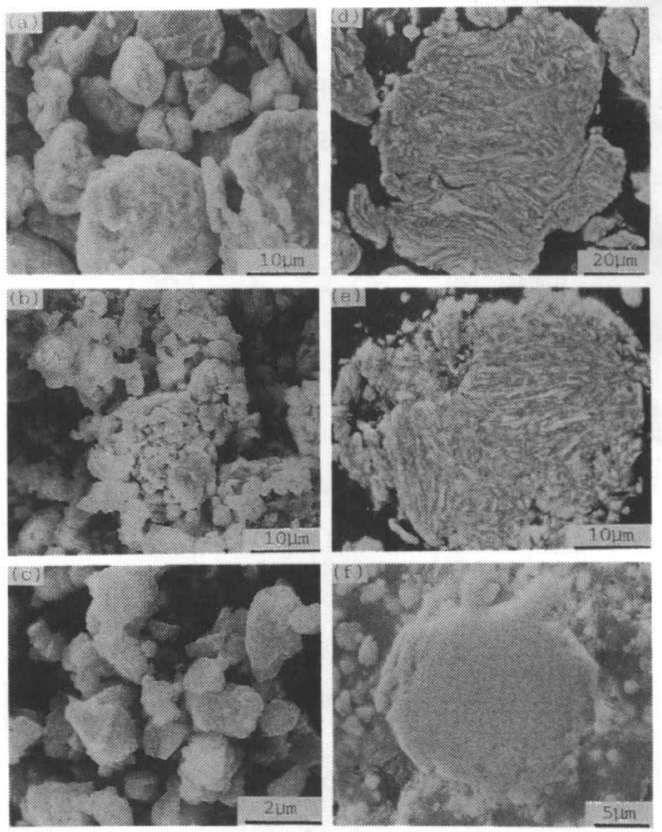

Photo. 1 SEM micrographs of $\mathrm{Al}-\mathrm{Nb}$ powders mechanically alloyed for various times.

(a)(b)(c) Shapes of the powder particles.

(d)(e)(f) Microstructures of the $\mathrm{sec}^{-}$ tioned particles

(a)(d)14. $4 \mathrm{ks},($ b) (e) $28.8 \mathrm{ks}$, (c)(f) $72.0 \mathrm{ks}$

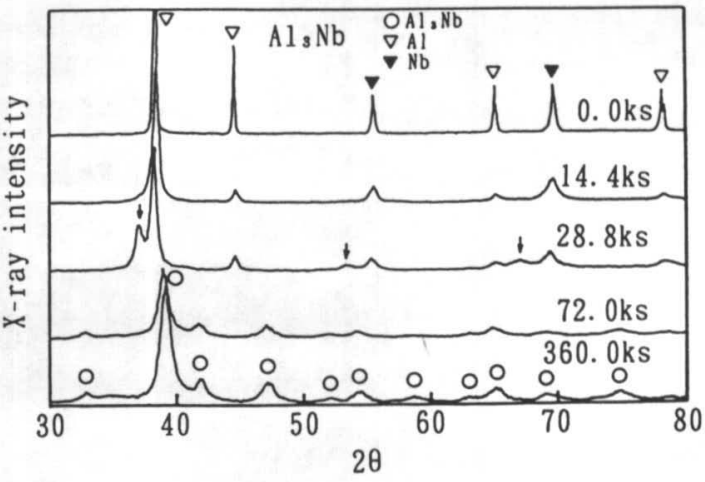

Fig. 1 X-ray diffraction patterns of $\mathrm{Al}-\mathrm{Nb}$ powders mechanically alloyed for various times.

一方, 72. 0ksMA処理を行うとA1, Nbの回折ピークは消失 し, $\mathrm{Al}_{3} \mathrm{Nb}$ 回折ピークのみが認められる.また，非常 にブロードではあるがNbCの回折ピークが認められた． 


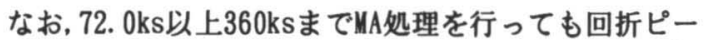
クはブロード化せず, 72.0ksMA処理粉末の回折図形と 比へててとんど変化が認められない，また，いずれの $\mathrm{X}$ 線回折図形においても $\mathrm{Nb}_{3} \mathrm{Al}, \mathrm{Nb}_{2} \mathrm{Al}$ のような $\mathrm{Al}_{3} \mathrm{Nb}$ 以

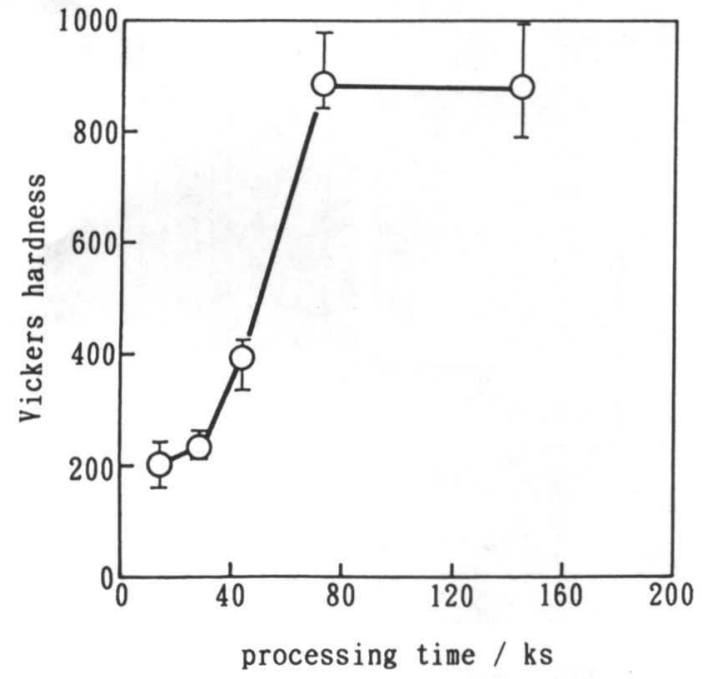

Fig. 2 Micro-Vickers hardness of Al-Nb MA powders as a function of MA processing time.
外の化合物相は認められなかった.

以上のように, MA処理時間が $72.0 \mathrm{ks}$ 前後で回折パ夕 一ンが急激に変化し，結晶質の金属間化合物相が得ら れることがわかった.

前述の28.8ksMA処理を行った粉末で現れる新たな回 折ピークについては, Nb粉末にメチルアルコールを添 加して同時間MA処理した粉末の回折ピークと一致する こと,さらにNb粉末を72.0ksまでMA処理した粉末の回

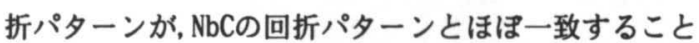
から, Nbに助剂のメチルアルコール中のCが固溶したた めに現れた回折ピークであることがわかった．また， MA粉末の炭素分析を行った結果, MA処理時間の增加に ともないC含有量は增加し, 最大 0.6 mass\%の侵入が認め られた．また，助剤のメチルアルコール量を同量とし， 粉末の量を $1 / 2$ とするとC含有量が倍增することからも， 含有している Cは主にメチルアルコールからのもので あることがわかった.

A1-Nb系MA粉末の MA処理時間にともなう硬さの変化 をFig. 2に示す. MA処理時間が40ksまではHv300前後の 比較的低い值を示しているが, 72ksになると約Hv900ま で硬さが急激に上昇し，それ以上で硬さの上昇が飽和
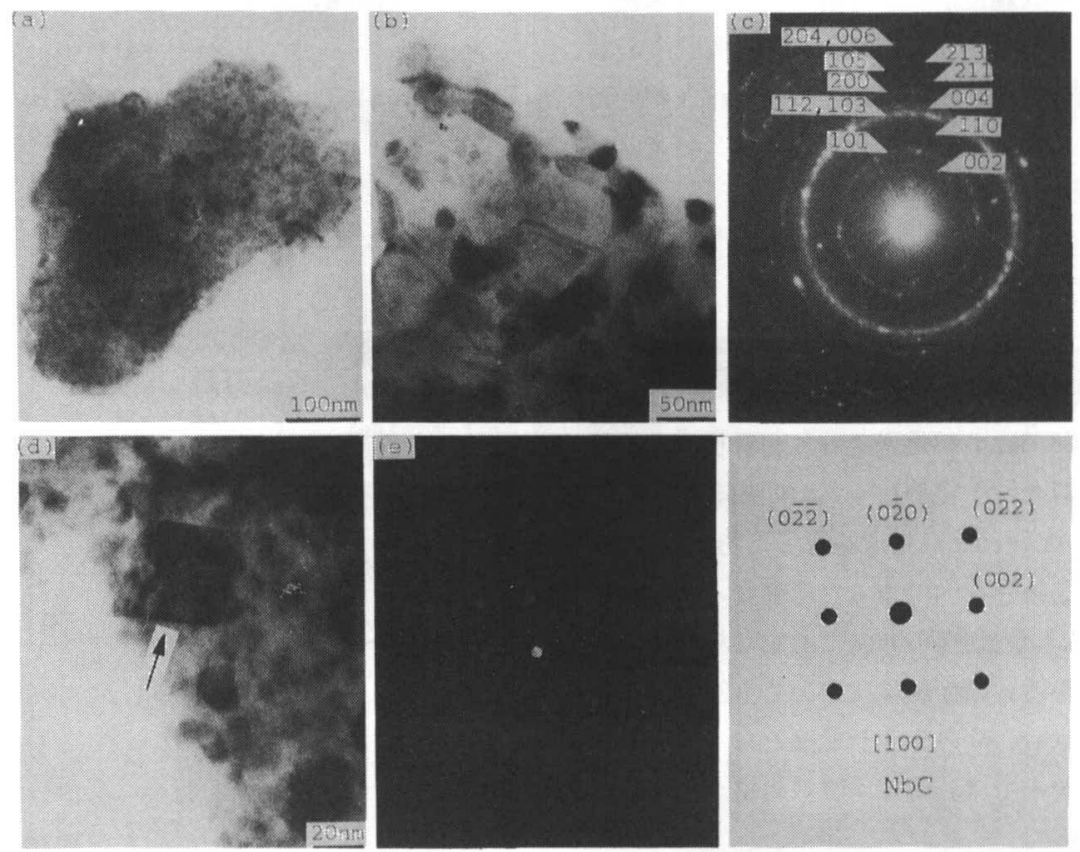

Photo. 2 TEM images and electron beam diffraction patterns of $\mathrm{Al}-\mathrm{Nb}$ powders mechanically alloyed for $72.0 \mathrm{ks}$.

(a)(b)(d) bright-field images.

(c) diffraction pattern obtained from (b).

(e) micro-diffraction pattern obtained from an arrow in (d). 
している.この急激な硬さの変化はX線回折の変化と よく対応しており, 主に $\mathrm{A} 1_{3} \mathrm{Nb}$ 生成が起因しているも のと考えられる. Photo. 2 にAl-Nb系MA粉末のTEM像 および電子線回折パターンを示す. (b)の制限視野回折 (SAD) パターン(c)は $\mathrm{A} 1_{3} \mathrm{Nb}$ ハリング状パターンを示し ており, ナノメータサイズの $\mathrm{Al}_{3} \mathrm{Nb}$ 結晶相が生成して いることがわかった. また, (d)の矢印で示した黒い析 出物は粉末粒子全体に均一に分散しており,そのマイク 口SADパターン(e)からNbCであることがわかった.

以上をまとめると, $\mathrm{A} 1$ およ゙゙ $\mathrm{Nb}$ 粉末を $\mathrm{A} 1_{8} \mathrm{Nb}$ の組成に 配合し，72.0ks以上のMA処理を行うことによりA1とNb が反応し, $\mathrm{Al}_{3} \mathrm{Nb}$ が生成されると同時に, $\mathrm{Nb}$ メチルア ルコール中のCが反応し， NbCが生成する，その結果， 数nmの NbCが微細に分散した $\mathrm{Al}_{3} \mathrm{Nb}$ 粉末が生成すること が明らかとなった。

$\mathrm{Al}$, Nbおよび黒鉿粉末を $\mathrm{A} 1_{3} \mathrm{Nb}-\mathrm{xvo1} \% \mathrm{NbC} （ \mathrm{x}=5,10,20$, 30）の組成に配合し，72.0ksMA処理を行った粉末（以 後, Al-Nb-C系MA粉末之呼ふ）のNbC配合率xの変化にと むなうX線回折図形の変化をFig. 3に示す.いずれの場

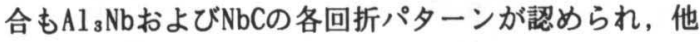
の化合物相の生成は認められない，また，xの增加にと むないNbCのピーク強度が増加し, NbC配合率に比例し て生成するNbC量が変化しているのがわかる.

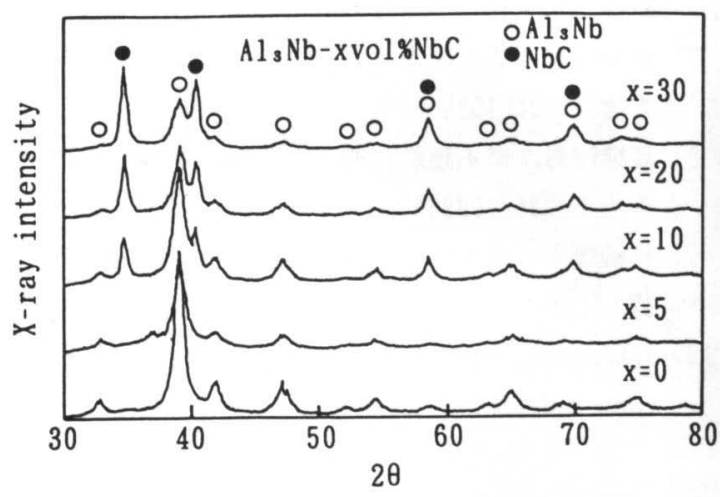

Fig. 3 X-ray diffraction patterns of $\mathrm{Al}-\mathrm{Nb}-\mathrm{C}$ powders mechanically alloyed for $72.0 \mathrm{ks}$.

MA処理時間 72. OksのA1-Nb系MA粉末およびA1-Nb-C系

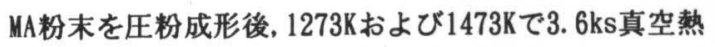
処理した圧粉体の硬さ測定結果をFig. 4に示す. ○およ

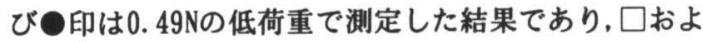
びロ印は4.9Nの比較的高荷重で測定した結果である.

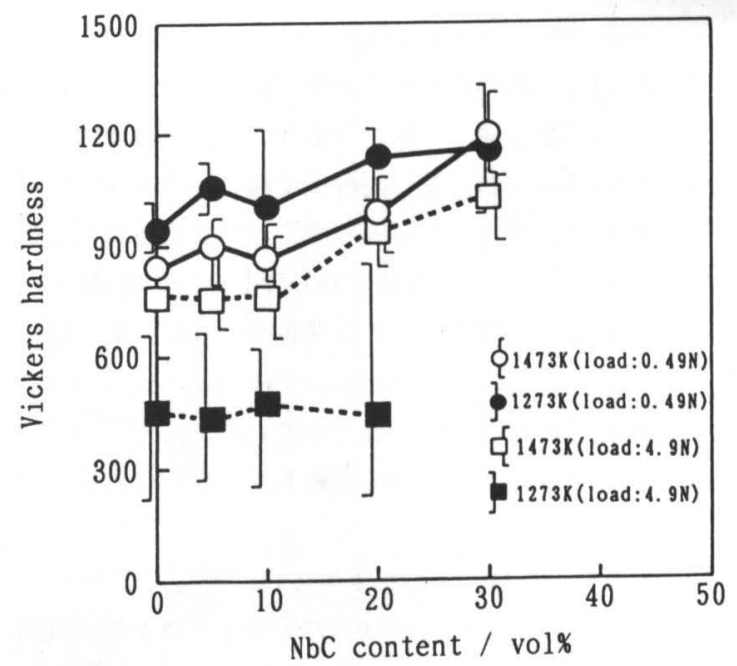

Fig. 4 Micro-vickers hardness of the sintered compacts of $\mathrm{Al}-\mathrm{Nb}-\mathrm{C}$ powders mechanically alloyed for $72.0 \mathrm{ks}$ as a function of $\mathrm{NbC}$ content.
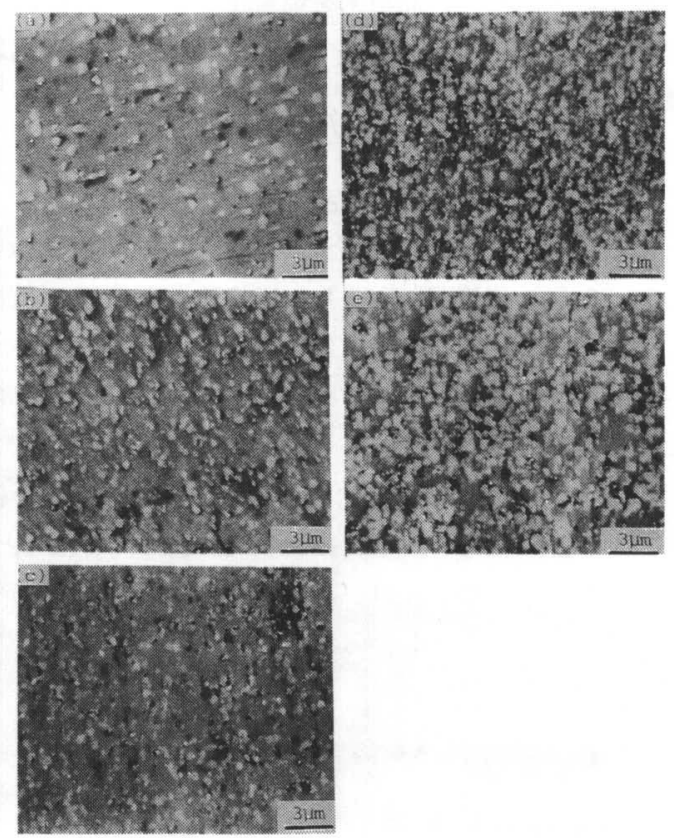

Photo. 3 SEM micrographs of the sintered compacts of $\mathrm{Al}-\mathrm{Nb}-\mathrm{C}$ powders mechanically alloyed for $72.0 \mathrm{ks}$.
(a) $\mathrm{Al}_{3} \mathrm{Nb}$
(d) $\mathrm{Al}_{3} \mathrm{Nb}-20 \mathrm{vol} \% \mathrm{NbC}$
(b) $\mathrm{Al}_{3} \mathrm{Nb}-5$ vol\% $\mathrm{NbC}$
(e) $\mathrm{Al}_{3} \mathrm{Nb}-30$ vol\% $\mathrm{NbC}$
(c) $\mathrm{Al}_{3} \mathrm{Nb}-10$ vol\% $\mathrm{NbC}$ 
低荷重で測定した場合，1273Kおよび1473Kで熱処理し た压粉体の硬さはともにHv1000前後で，愹製材の硬さ が約Hv750 ${ }^{10)}$ なのに比へてかなり高い值を示している。 さらに, NbC配合率の增加にともない硬さが直線的に上 昇しているのがかかる．高荷重で測定した場合，1473K で焼結した圧粉体が低荷重で測定した值とほぼ同じ硬 さであるのに対し，1273Kで熱処理した圧枌体はHv500 と低い値を示し,NbC配合率に関係なくほほ一定の値を 示している.このことは, 1473Kでは焼結がかなり進ん でおり維密な焼結体が作製できているのに対し.1273K では粉末粒子同士が十分に焼結していないことを示唆 している.

1473Kで真空熱処理した圧粉体の断面組織をPhoto. 3 に示す.いずれの断面組織も若干のミクロポアが見ら れるものの維密な焼結体が得られている、また，白っ ぽく見えるサブミクロンサイズの析出物が認められ， $\mathrm{NbC}$ 配合率xの增加にともない，析出物の量は增加して

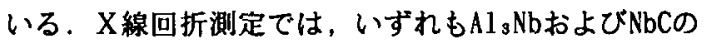
各回折ピークがシャープになっているのみで, 他の化 合物相は認められなかった。

以上の結果から，MA粉末を焼結することによりサブ ミクロンサイズのNbCが均一微細に分散したA1s $\mathrm{Nb}$ 金属 間化合物を作製できることが明らかとなった。

\section{4 まとめ}

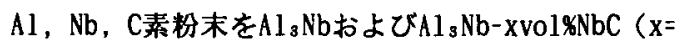
$5,10,20,30)$ の組成に配合し，MA処理を行った。一部 のMA粉末については压粉成形後，真空熱処理を行った。 得られた粉末および焼結体について組織観察，相の同 定，硬さ測定を行った．得られた結果を以下に示す。

(1) $\mathrm{A} 1 s \mathrm{Nb}$ の組成に配合し，MA処理を行った場合, 72.0 ks以上の処理時間でA ${ }_{3} \mathrm{Nb}$ 相が生成し, 同時にNbと 助剂のメチルアルコール中のCが反応し，NbCが形 成されることがわかった。
（2）TEM鹳察により，MA粉末中にナノメータサイスの微 細なA1s $\mathrm{Nb}$ 相およびNbC粒子が生成していることが 認められた。

（3）A1，Nb，C素粉末を用い， $\mathrm{A} 1_{s} \mathrm{Nb}-\mathrm{x}$ vol*NbC（x=5，10， 20，30）に配合し，72.0ksMA処理を行うことによっ て、配合率に必じた微細なNbCが分散したA1 $\mathrm{N}$ Nb枌 末を作製することができた。

（4）MA粉末を圧粉成型し，1473Kで真空熱処理すること により NbCが微細に分散した $\mathrm{A}_{3} \mathrm{Nb}$ 緻密な焼結体 を作製することができた。

（5）焼結材の硬さはHv1000前後の高い值を示し, NbC体 皘率の增加にともない上昇する傾向が認められた．

\section{文献}

1) J.S. Benjamin and T.E. Volin: Metall. Trans., 5(1974)1929.

2) G. H. Gessinger: Metall. Trans., 7A(1976)1203.

3) J.S. Benjamin and M. J. Bomford: Metall. Trans., 8A(1977)1301.

4) C. C. Koch, O. B. Cavin, C. G. Mckamey and J. D. Scarbrough: Appl. Phys. Lett., 43(1983)1017.

5) E. Ivanov, T. Grigrieva, G. Golubkova, V. Boldyrev, A. B. Fasman, S. D. Mikhai lenko and 0. T. Kalinina: Hater. Lett. , 7(1988)51.

6) C. C. Koch and K.S. Kim: J. Physique, 46(1985) 573.

7）高橋揮男, 㧺本雍彦, 香山滉一郎：枌体および粉 末治金, 36(1989)404.

8）高橋蟫男, 橋本雍彦, 香山滉一郎: 粉体および扮 末冶金, 36(1989)837.

9）高橋輝男，橋本雍彦：日本金属学会誌，54(1990) 67.

10) J. L. Jorda, R. F1ukiger and J. Huller : J.LessCommon Met., 75(1980)227. 